\title{
Are Kenya Meteorological Department heavy rainfall advisories useful for forecast-based early action and early preparedness for flooding?
}

\author{
David MacLeod ${ }^{1,2}$, Mary Kilavi ${ }^{3}$, Emmah Mwangi $^{4}$, Maurine Ambani $^{4}$, Michael Osunga $^{4}$, Joanne Robbins $^{5}$, \\ Richard Graham ${ }^{5}$, Pedram Rowhani ${ }^{6}$, and Martin C. Todd ${ }^{6}$ \\ ${ }^{1}$ Atmospheric Oceanic and Planetary Physics, Department of Physics, University of Oxford, Oxford OX13PU, UK \\ ${ }^{2}$ School of Geographical Sciences, University of Bristol, BS8 1SS, UK \\ ${ }^{3}$ Kenya Meteorological Department (KMD), Nairobi 00100 GPO, Kenya \\ ${ }^{4}$ Kenya Red Cross Society, Nairobi 00100 GPO, Kenya \\ ${ }^{5}$ Met Office, Exeter EX1 3PB, UK \\ ${ }^{6}$ Department of Geography, University of Sussex, Brighton BN1 9QJ, UK
}

Correspondence: David MacLeod (david.macleod@bristol.ac.uk)

Received: 14 April 2020 - Discussion started: 27 April 2020

Revised: 16 October 2020 - Accepted: 26 November 2020 - Published: 25 January 2021

\begin{abstract}
Preparedness saves lives. Forecasts can help improve preparedness by triggering early actions as part of predefined protocols under the Forecast-based Financing $(\mathrm{FbF})$ approach; however it is essential to understand the skill of a forecast before using it as a trigger. In order to support the development of early-action protocols over Kenya, we evaluate the 33 heavy rainfall advisories (HRAs) issued by the Kenya Meteorological Department (KMD) during 2015-2019.

The majority of HRAs warn counties which subsequently receive heavy rainfall within the forecast window. We also find a significant improvement in the advisory ability to anticipate flood events over time, with particularly high levels of skill in recent years. For instance actions with a 2-week lifetime based on advisories issued in 2015 and 2016 would have failed to anticipate nearly all recorded flood events in that period, whilst actions in 2019 would have anticipated over $70 \%$ of the instances of flooding at the county level. When compared against the most significant flood events over the period which led to significant loss of life, all three such periods during 2018 and 2019 were preceded by HRAs, and in these cases the advisories accurately warned the specific counties for which significant impacts were recorded. By contrast none of the four significant flooding events in 2015-2017 were preceded by advisories. This step change in skill may be due to developing forecaster experience with
\end{abstract}

synoptic patterns associated with extremes as well as access to new dynamical prediction tools that specifically address extreme event probability; for example, KMD access to the UK Met Office Global Hazard Map was introduced at the end of 2017.

Overall we find that KMD HRAs effectively warn of heavy rainfall and flooding and can be a vital source of information for early preparedness. However a lack of spatial detail on flood impacts and broad probability ranges limit their utility for systematic $\mathrm{FbF}$ approaches. We conclude with suggestions for making the HRAs more useful for $\mathrm{FbF}$ and outline the developing approach to flood forecasting in Kenya.

\section{Introduction}

Like many worldwide the Kenyan population is at significant risk from heavy rainfall-induced flooding. In the last 2 years alone flood losses and damages have been extensive. Recent examples of this include flooding during the "long rains" season of 2018, impacts of which included the displacement of 300000 people (OCHA, 2018). This was shortly followed by the "short rains" flooding of 2019, which induced a landslide in West Pokot, killing 72 (reliefweb, 2019). In response to this kind of hydro-meteorological risk, 
the Red Cross Red Crescent movement has pioneered the Forecast-based Financing approach (FbF; see https://www. forecast-based-financing.org/, last access: 11 January 2021, for more details).

In the humanitarian action landscape $\mathrm{FbF}$ sits within a wider set of approaches to anticipatory risk management, which can broadly be termed early warning-early action, of which there are many examples (see Wilkinson et al., 2018, for a review of $\mathrm{FbF}$ initiatives). FbF specifically has three defining features: a set of objective pre-defined forecast triggers, which when met activate a set of pre-defined early actions, themselves funded by a dedicated finance mechanism. Together these constitute the early-action protocols (EAPs) of an FbF system. The EAPs can facilitate early actions (such as evacuation or cash transfers) or readiness actions (such as pre-positioning of non-food items) which can be implemented before the hazard event occurs, thus moving from disaster response to early preparation and reduction in potential risks posed by the hazard event. Many FbF pilots are active worldwide, and whilst it is not simple to precisely quantify the impact of such programmes, evidence suggests they can significantly reduce individual and community expenses (Gros et al., 2019) along with bringing unquantifiable benefits to lives and livelihoods.

Following the establishment of the DREF (Disaster Risk Emergency Fund) by the International Federation of Red Cross and Red Crescent Societies in December 2017, national Red Cross and Red Crescent societies are working to define their EAPs for the dominant hazard types. In Kenya this work is facilitated through the project "Innovative Approaches in Response Preparedness" (IARP), funded by the IKEA Foundation and implemented by the Kenya Red Cross Society (KRCS) with further support from aligned projects, notably the UK-funded NERC (Natural Environment Research Council) and DFID (Department for International Development) project "Toward Forecast-Based Preparedness Action" (ForPAc3; http://www.forpac.org, last access: 11 January 2021). ForPAc has been working since 2017 with partners including the Kenya Meteorological Department (KMD) and KRCS to establish the scientific basis for $\mathrm{FbF}$ and investigate the development of anticipatory approaches in Kenya for managing flood and drought risk across a range of forecast timescales.

Setting up an FbF EAP for a particular hazard begins by identifying priority risks or impacts that can be addressed by anticipatory early action. The next step is to identify the best forecasts to use to trigger early action. In Kenya under the IARP programme, this involved exploring a range of potential forecasts that can support anticipation of the priority risks and evaluating the accuracy (or skill) of the forecasts. Anticipatory actions are then selected which are consistent with the skill of the forecast. For instance a reliable forecast of extremely high probability of imminent flooding might be an appropriate trigger for a higher-cost intervention such as evacuation, whilst a lower probability level (with a higher chance of action in vain) could still be linked to a lower-cost or "no-regret" action such as repair of river dykes.

Forecast skill assessment is therefore an essential step in designing a system for FbF. In order to be used (in this case by the KRCS and national disaster management agencies), forecasts must show evidence of skill, which should be quantified. In addition the forecast must be readily available to the actors from the mandated agency for providing weather forecasts (in this case the KMD). Finally the forecast must be provided in such a way to be easily integrated within the EAP.

Through the IARP programme a "menu" of potential forecasts of flood risk has been developed for the Kenya EAPs. In the absence of a Kenya-wide national flood forecast system (Weingärtner et al., 2018), forecasts of rainfall provide the most appropriate proxy. One key potential forecast for heavy rainfall events that could result in flooding is the KMD heavy rainfall advisories (HRAs; described in full in Sect. 2.1). These text-based advisories are issued on an irregular basis by the KMD when forecasters' interpretation of current conditions and the output of dynamical atmospheric models point to risk of heavy rainfall. These advisories are made widely available to the public and risk management agencies in relevant counties.

As these heavy rain advisories are issued from the mandated forecasted agency, they have high potential to be used in a systematic manner as an FbF trigger in flood EAPs. However the skill of these advisories is unknown. In addition they are developed explicitly for heavy rainfall warnings and only implicitly warn of flooding. Here then we assess the accuracy of the historically issued KMD HRAs and evaluate their potential to be used as a trigger in an $\mathrm{FbF}$ system for flooding. Understanding the level of skill of the advisories supports the development of early-action protocols by disaster managers.

The verification of the advisories also helps to build confidence in early warnings from subjective forecasts. Many forecasts of natural hazards are produced with some level of expert judgement, but this subjectivity makes verification difficult as a large number of forecasts produced using a consistent method are rarely available for objective evaluation. Without this evaluation, trust in the forecast producer alone determines confidence in the forecasts. However when a reasonable archive of forecasts is available, forecast verification can help both to build confidence in the use of the forecasts and to increase trust in the forecast producer.

The forecast and verification data are described in the following section, along with an outline of the challenges to verification posed by the format of the advisories and the approach taken to meet this challenge. Results follow, and the paper concludes with a discussion of the main findings and limitations to the analysis along with recommendations for design and operation of the Kenya EAPs and further research. 


\section{Data and verification approach}

\subsection{Production of the KMD heavy rainfall advisories}

The first HRA was issued at the KMD on 2 June 2015 after being introduced as a forecast product as part of the Severe Weather Forecasting Demonstration Project (SWFDP) for East Africa (https://www.wmo.int/pages/prog/www/swfdp/ SWFDP-EA.html, last access: 11 January 2021). This project was implemented with support from the World Meteorological Organization (WMO) with the aim of improving the ability of National Meteorological and Hydrological Services (NMHSs) to forecast severe-weather events and improve the lead time of early warnings as well as the interaction of NMHSs with disaster managers before and during the event. The intended audiences for these advisories are national and county risk management agencies, humanitarian organizations, relevant ministries, and the media for dissemination to the general public within areas of concern.

The decision to issue an advisory is subjective, informed by dynamical model output and forecaster experience. Every day forecasters at the KMD's Severe Weather Forecasting section review forecast products from Global Producing Centres (such as the European Centre for MediumRange Weather Forecasts, ECMWF; National Centers for Environmental Prediction, NCEP; UK Met Office; and Meteo France) using their judgement to produce a $5 \mathrm{~d}$ running severe-weather forecast. This $5 \mathrm{~d}$ severe-weather forecast is based on areas expected to receive any of the following: rainfall above $50 \mathrm{~mm}$ in $24 \mathrm{~h}$, winds greater than 25 knots, or waves above $2 \mathrm{~m}$ height. These forecasts are presented graphically as polygons, along with tables showing the level of risk (low, medium, or high) over specified areas. At 09:00 Z representatives from the NMHSs of all the contributing countries of the SWFDP participate in a teleconference call to discuss the forecast and develop a consensus.

If any models indicate a raised chance of an extreme event occurring over Kenya during the next few days, then a high-impact weather conference is held at the KMD by experts from the forecasting unit, and a consensus advisory is drafted. A subjective probability of occurrence is estimated based on the consensus between models, taking into account weighting of the better-performing models (where model quality is judged subjectively according to forecasters' experience). Once the advisory is drafted it is examined and reviewed by the senior management within the forecasting division and finally sent to the director for approval to disseminate it to the public by the public weather service section.

HRAs are the most frequently issued type of advisory by the KMD (advisories for strong winds, ocean waves, and temperature are also issued but are not considered in this study). The advisories are text-based (an example is shown in Fig. 1). They generally specify a rainfall threshold which could be reached: sometimes this is included as a rainfall rate (e.g. $30 \mathrm{~mm}$ in $24 \mathrm{~h}$ ), otherwise an accumulation total without a rate is mentioned. Finer-scale details are often included in this description, such as when within the valid period the rainfall can be expected to start for different regions. Following the forecast description, the full list of potentially affected counties is listed, along with general instructions for flood preparedness (e.g. "be on the lookout for potential floods", "avoid driving through or walking in moving water", "people in landslide prone areas ... should be on high alert").

There are no clear objective criteria triggering issuance of HRAs, which is a subjective process depending on forecasters' experience and perception of model skill, consensus within the forecasting section, and forecast data available. The forecast information used at the KMD to produce the HRAs has changed over the advisory period under study: in mid-2016, the KMD was granted a 2-year trial license to ECMWF "eccharts" through the SWFDP, and in August 2017 the KMD began using the UK Met Office Global Hazard Map (GHM) as part of the ForPAc project. The GHM provides an at-a-glance summary of forecast high-impact weather over the coming week by visualizing forecasts from the UK Met Office (MOGREPS-G, which is the Met Office Global and Regional Ensemble Prediction System) and ECMWF (ENS), both separately and in a multi-model ensemble forecast. The multi-model informs summary polygons which direct forecasters to the potential for high-impact weather over the week ahead via an overview map.

By the end of 2019 a total of 33 HRAs had been issued. These 33 have been digitized here for the purpose of verification, with relevant information extracted: the date of issue and validity, the probability range, and the rainfall threshold specified along with all counties mentioned. Details are given in Table 1, and descriptive statistics are shown in Fig. 2. Several aspects of the KMD advisories demand a careful approach to verification, as detailed in the following section.

\subsection{Verification approach}

There are three characteristics of the HRAs with implications for verifying them against observed rainfall:

1. The small sample size (33) means it is difficult to assess specific aspects of the forecast such as reliability of probabilities or accuracy of rainfall thresholds. Descriptive statistics for these are provided in Fig. 2, which shows that the probability range of " $33 \%-66 \%$ " is indicated in nearly all advisories (Fig. 2d; used in 26 advisories), and other probability ranges are rarely used.

2. The forecast window over which advisories are active is variable from 1 to $6 \mathrm{~d}$ but most commonly out to $3 \mathrm{~d}$ (Fig. 2c; 13 advisories), so the definition of heavy rainfall for verification cannot be consistent.

3. The spatial characteristics of the forecasted heavy rainfall are ambiguous. To illustrate: should we deem an 


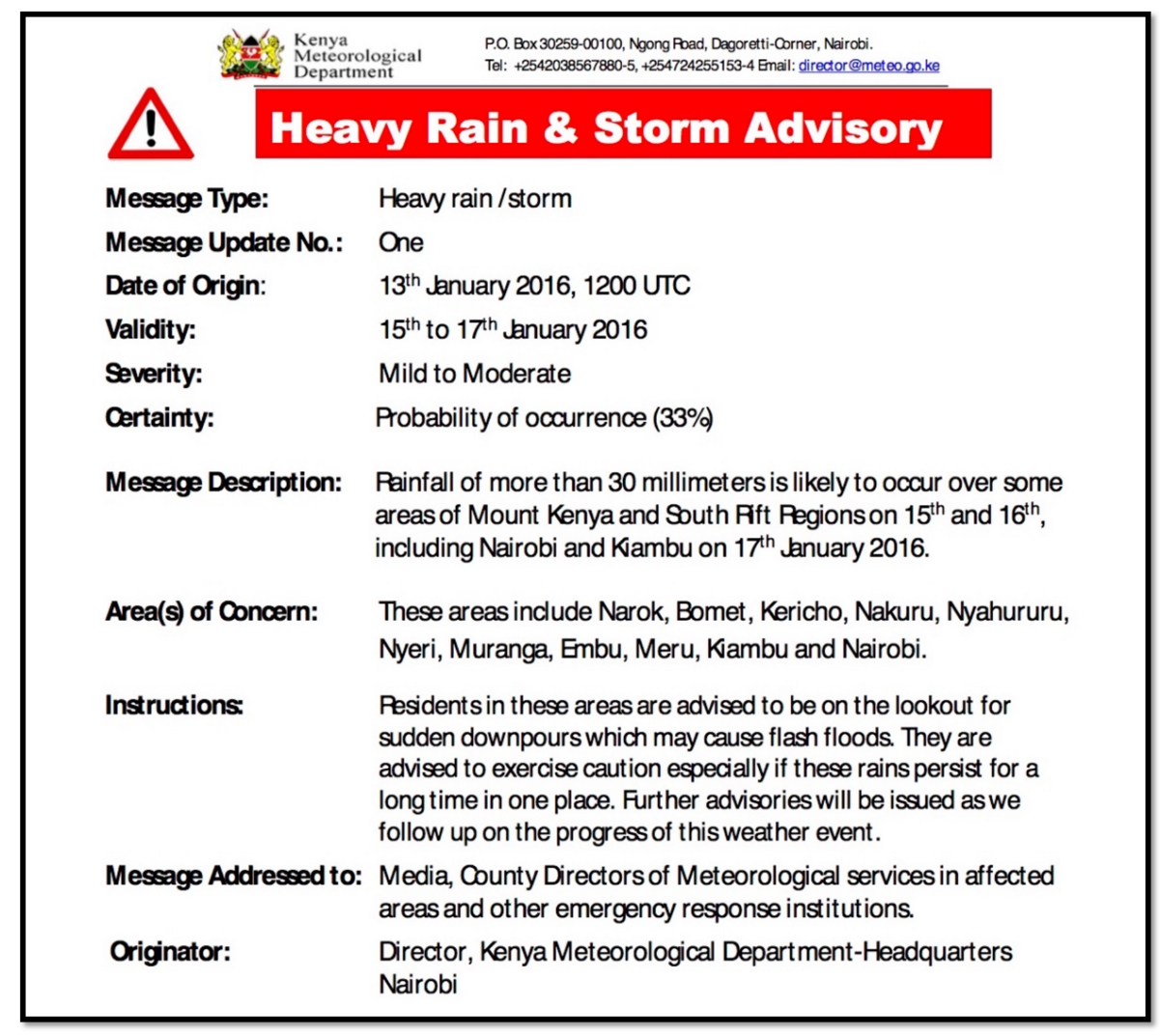

Figure 1. An example of a heavy rainfall advisory issued by the KMD.
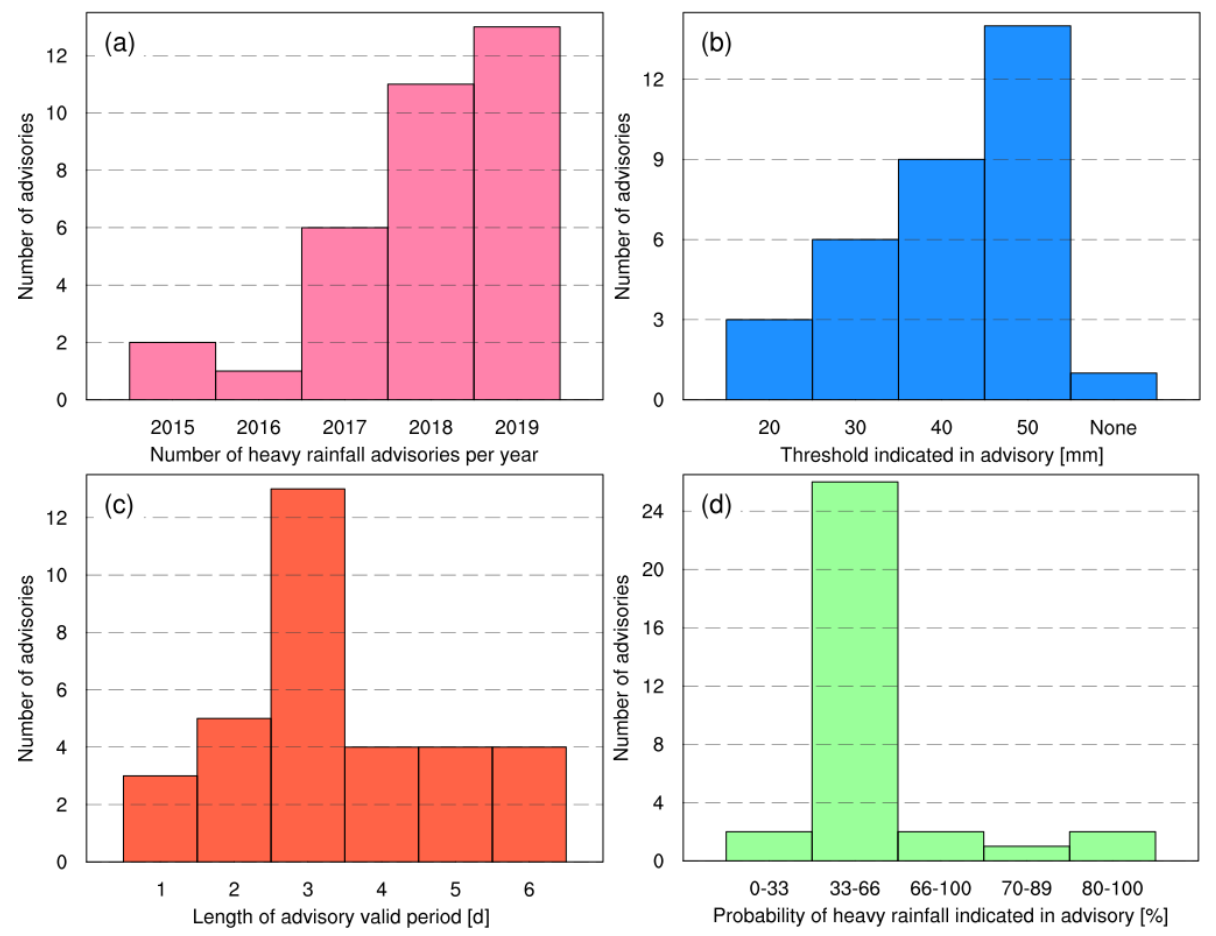

Figure 2. Summary statistics of advisories issued over 2015-2019 detailed in Table 1. (a) The number of advisories issued per year, (b) the rainfall threshold mentioned, (c) the length of the valid period, and (d) the probability mentioned. 
Table 1. Summary of all advisories 2015-2019 evaluated in this study.

\begin{tabular}{|c|c|c|c|c|}
\hline Label & Issue date & $\begin{array}{l}\text { Period length } \\
\quad \text { (days) }\end{array}$ & $\begin{array}{l}\text { Largest rainfall } \\
\text { threshold mentioned }\end{array}$ & Probability indicated \\
\hline A & 2 June 2015 & 2 & $50 \mathrm{~mm}$ & $33 \%-66 \%$ \\
\hline B & 2 July 2015 & 2 & $50 \mathrm{~mm}$ & $0 \%-33 \%$ \\
\hline $\mathrm{C}$ & 25 April 2016 & 2 & $50 \mathrm{~mm}$ & $80 \%-100 \%$ \\
\hline $\mathrm{D}$ & 18 April 2017 & 2 & $50 \mathrm{~mm}$ & $33 \%-66 \%$ \\
\hline $\mathrm{E}$ & 28 April 2017 & 1 & $50 \mathrm{~mm}$ & $70 \%-89 \%$ \\
\hline $\mathrm{F}$ & 18 September 2017 & 3 & $50 \mathrm{~mm}$ & $80 \%-100 \%$ \\
\hline $\mathrm{G}$ & 11 October 2017 & 3 & $50 \mathrm{~mm}$ & $33 \%-66 \%$ \\
\hline $\mathrm{H}$ & 30 October 2017 & 2 & $50 \mathrm{~mm}$ & $33 \%-66 \%$ \\
\hline I & 2 November 2017 & 4 & $30 \mathrm{~mm}$ & $66 \%-100 \%$ \\
\hline $\mathrm{J}$ & 27 February 2018 & 3 & $50 \mathrm{~mm}$ & $33 \%-66 \%$ \\
\hline K & 9 March 2018 & 4 & $40 \mathrm{~mm}$ & $0 \%-33 \%$ \\
\hline $\mathrm{L}$ & 15 March 2018 & 4 & $50 \mathrm{~mm}$ & $66 \%-100 \%$ \\
\hline M & 27 April 2018 & 5 & $40 \mathrm{~mm}$ & $33 \%-66 \%$ \\
\hline $\mathrm{N}$ & 2 May 2018 & 3 & $50 \mathrm{~mm}$ & $33 \%-66 \%$ \\
\hline $\mathrm{O}$ & 7 May 2018 & 3 & $50 \mathrm{~mm}$ & $33 \%-66 \%$ \\
\hline $\mathrm{P}$ & 20 May 2018 & 1 & $50 \mathrm{~mm}$ & $33 \%-66 \%$ \\
\hline Q & 30 May 2018 & 1 & $30 \mathrm{~mm}$ & $33 \%-66 \%$ \\
\hline $\mathrm{R}$ & 4 June 2018 & 3 & $40 \mathrm{~mm}$ & $33 \%-66 \%$ \\
\hline S & 24 September 2018 & 3 & $50 \mathrm{~mm}$ & $33 \%-66 \%$ \\
\hline $\mathrm{T}$ & 23 October 2018 & 3 & $40 \mathrm{~mm}$ & $33 \%-66 \%$ \\
\hline $\mathrm{U}$ & 25 March 2019 & 3 & $30 \mathrm{~mm}$ & $33 \%-66 \%$ \\
\hline V & 3 May 2019 & 4 & $40 \mathrm{~mm}$ & $33 \%-66 \%$ \\
\hline W & 7 May 2019 & 5 & $30 \mathrm{~mm}$ & $33 \%-66 \%$ \\
\hline $\mathrm{X}$ & 22 Маy 2019 & 3 & $40 \mathrm{~mm}$ & $33 \%-66 \%$ \\
\hline $\mathrm{Y}$ & 31 May 2019 & 6 & $40 \mathrm{~mm}$ & $33 \%-66 \%$ \\
\hline $\mathrm{Z}$ & 10 October 2019 & 5 & $20 \mathrm{~mm}$ & $33 \%-66 \%$ \\
\hline $\mathrm{A}^{\prime}$ & 14 October 2019 & 5 & $40 \mathrm{~mm}$ & $33 \%-66 \%$ \\
\hline $\mathrm{B}^{\prime}$ & 23 October 2019 & 6 & $20 \mathrm{~mm}$ & $33 \%-66 \%$ \\
\hline $\mathrm{C}^{\prime}$ & 18 November 2019 & 6 & $40 \mathrm{~mm}$ & $33 \%-66 \%$ \\
\hline $\mathrm{D}^{\prime}$ & 23 November 2019 & 3 & $30 \mathrm{~mm}$ & $33 \%-66 \%$ \\
\hline $\mathrm{E}^{\prime}$ & 28 November 2019 & 6 & $30 \mathrm{~mm}$ & $33 \%-66 \%$ \\
\hline $\mathrm{F}^{\prime}$ & 3 December 2019 & 3 & None & $33 \%-66 \%$ \\
\hline $\mathrm{G}^{\prime}$ & 6 December 2019 & 3 & $20 \mathrm{~mm}$ & $33 \%-66 \%$ \\
\hline
\end{tabular}

advisory warning of $50 \mathrm{~mm}$ of rainfall for two named counties to be a "hit" if $50 \mathrm{~mm}$ accumulated rainfall is observed (a) over a single point within at least one of the counties, (b) over the entirety of either or both counties, or (c) any areal extent between these extremes? This spatial aspect is further complicated by the wide range of size of Kenyan counties: from just over $200 \mathrm{~km}^{2}$ (Mombasa) to over $70000 \mathrm{~km}^{2}$ (Turkana). The hit rate and false-alarm rate would be highly sensitive to these verification criteria.

In order to address these issues, we take a step back and refocus on the question of whether these advisories would have been worthwhile for flood preparedness. Though "heavy rainfall" does not necessarily lead to flooding, and flooding does not always require a heavy rainfall event for triggering (Berghuijs et al., 2019), we proceed by considering the perspective of a manager responsible for flood preparedness at the KRCS who is interested in the consequences of using the advisories as a trigger for preparedness.

We first assume that every advisory triggers preparedness actions independent of the rainfall threshold or probability specified. We then define the extent of the preparedness actions according to the counties mentioned in the advisory. Such actions are unspecified here and could range from a low-regret communication to county-level Red Cross volunteers to a more expensive decision to pre-position supplies. This approach is consistent with the FbF approach, though with action triggered on the release of an advisory rather than being associated with a particular probability level.

After assuming that action was taken within the entire region under advisory for each advisory window, we then consider the question of whether this action was worthwhile. There is no single answer to this question as it depends on the specific actions along with individual and institutional tolerances for false alarms and misses. However following this 
approach we can identify clear hits and false alarms and can confront the advisories with "what really happened". As such our method involves answering the following four questions:

1. How well does the total area under advisory warn of the extent of heavy rainfall? (Sect. 3.1)

2. What is the relative spatial extent of preparedness actions implied by each advisory? (Sect. 3.2)

3. How many flooding events in the period 2015-2019 would the advisories have anticipated? (Sect. 3.3)

4. How often would an FbF system based on the advisories be expected to trigger? (Sect. 3.4)

By answering these questions we determine the extent to which the KMD HRAs could effectively guide preparedness activity.

\subsubsection{Comparing advisory areas with subsequent rainfall}

We address question 1 with a visual comparison of the total area warned under each advisory with the total rainfall accumulation in the subsequent advisory window. Rainfall observations are taken from the Climate Hazards and Infra-Red Precipitation Data with Stations (CHIRPS) dataset (Funk et al., 2015). We use CHIRPS as it compares favourably against other rainfall datasets over East Africa and benefits from relatively high station density in Kenya (Dinku et al., 2018). Particular weaknesses of CHIRPS include spurious drizzle and underestimation of peak magnitudes of the most extreme rainfall (specifically the 99.9th percentile; Beck et al., 2017), but our focus on multi-day accumulation of heavy but not necessarily extreme rainfall should be insensitive to these biases.

With this visual comparison we begin with a subjective assessment of the overall performance of advisories. Following this we calculate the distribution of accumulation totals across all $5 \mathrm{~km}$ CHIRPS grid points inside the polygon associated with the warned counties, quantifying the spatial extent of high rainfall totals for areas under advisory. In addition we show the distribution as the percentage of grid points within the warned region receiving more than a specified rainfall threshold. Throughout the analysis we evaluate the total rainfall accumulation across each variable-length advisory window.

In addition we derive the proportion of the warned area that experienced accumulated rainfall above indicative thresholds. No single rainfall threshold leads to increased flood risk, which depends on many factors, both hydrometeorological and social. Even for a single location the same amount of rainfall may cause a flood in one year but not the next. In the following analysis we show results for 25, 50, 75 , and $100 \mathrm{~mm}$ accumulation over the advisory window and focus the discussion on results for $50 \mathrm{~mm}$ accumulation. We do not suggest that this threshold has primacy over others; an in-depth analysis would be necessary to determine and quantify the most relevant thresholds for flood risk in a location. Instead we take $50 \mathrm{~mm}$ as a working definition of heavy rainfall to keep the discussion concise whilst including other thresholds in the analysis for reference.

\subsubsection{Estimating the relative extent of preparedness actions implied by advisories}

To answer question 2 we estimate the relative scale of preparedness implied by each advisory. In practice preparedness actions would be determined by overlaying the forecast hazard footprint with data on exposure and vulnerability to that hazard. Many different actions are possible which would target different groups, and we do not attempt to evaluate the cost of specific actions. Instead we aim at a broad indication of the magnitude of the general preparedness activities appropriate for each advisory by assuming that preparedness is taken based on advisories to target communities exposed to a 1-in-5-year riverine flood event.

We use ward-level exposure data provided by the KRCS, which have been created by combining population density with an estimate of the areas inundated by a 1-in-5-year flood which has been provided to the KRCS by the ECMWF and calculated using the modelling framework of the Global Flood Awareness System (GloFAS). The exposure estimate is not intended to quantify the absolute level of assistance required (not least because the frequency of advisory issuance means that the vast majority will not be followed by a 1in-5-year event by definition). However it does allow a relative estimate of the extent of preparedness action required between advisories. For instance an advisory active in locations where 2 million people are exposed to flooding is likely to require more preparedness than an advisory relevant for only 200000 people. It should also be noted that the number exposed to flooding is an upper bound on those actually requiring assistance as we do not take vulnerability to flooding into account.

We then assess the amount of rainfall falling in the specific areas where people are exposed to flooding and estimate the percentage of the "prepared people" who received above-threshold rainfall. From this we can estimate the relative "worthiness" of each preparedness action: assuming that when flood preparedness assistance is given in a location, and significant rainfall follows, the action is considered worthy (even if that heavy rainfall does not lead to flooding). We note the potential mismatch between local rainfall and flooding (e.g. when rainfall falls upstream in the catchment and floods the lower reaches of the river), which suggests that our assumption of worthiness only when heavy rainfall is experienced locally should be considered a lower bound; inclusion of flooding related to non-local rainfall would only increase the estimate of worthiness. 


\subsubsection{Verifying HRAs against flood events and evaluating frequency of action triggering}

The analysis so far quantifies the extent of rainfall accumulations and estimates the relative scale of the actions which each advisory may trigger. Whilst heavy rainfall is not the only factor in flooding (Amoako and Frimpong Boamah, 2015) and does not always trigger flooding, flood risk and response managers may be inclined to use the HRAs to trigger readiness activities for flooding. It is therefore instructive to verify the issued HRAs directly against recorded flood events, answering question 3 above. We use two sources of flood records, and their use in verifying the advisories is described below.

The first flood record database has been created by the KRCS. This comprises a county-level record of flood events based on information from the KRCS Emergency Operations Center (EOC). The EOC operates $24 \mathrm{~h}$ a day at KRCS headquarters and records disaster incidences that are recorded all over the country on social and mainstream media and by KRCS volunteers. The record from the EOC has been supplemented with additional events identified post hoc from other online sources. In total over the 5 years 2015-2019, the database notes 461 flood events, with $167,44,54,164$, and 199 for each year separately (we note that simultaneous flooding in two counties is considered in this count as two events).

The KRCS flood record is then used to calculate two key skill statistics across the entire sample (over all counties): firstly the hit rate (HR), calculated here as the percentage of events which were preceded by advisories. Secondly we calculate the precision, which is defined as the percentage of advisories which are followed by a flood event (NB precision is equal to $100 \%$ minus the false-alarm ratio, another key metric for $\mathrm{FbF}$, and is a commonly used diagnostic in informatics; Powers, 2011). HR and precision are calculated over the whole sample and for each year separately. Following Coughlan de Perez et al. (2016) they are also calculated under the assumption that actions related to flood preparedness have a lifetime; that is, preparedness carried out today will still avert flood risk even if that flooding does not occur immediately. Actions such as evacuation will only remain effective whilst people remain evacuated, whilst lowregret actions focused on readiness such as pre-positioning of water purification tablets will still be useful if flooding occurs months later. Coughlan de Perez et al. (2016) use a $30 \mathrm{~d}$ lifetime in their verification; here we evaluate the advisories across a range of action lifetimes from 0 to $30 \mathrm{~d}$ following the end of the advisory window.

The second source of flood record we use is the EM-DAT database (EM-DAT, 2020). EM-DAT collects data on the occurrence and effects of mass disasters globally, requiring at least one of the following four conditions for inclusion in the database:
- 10 or more people dead;

- 100 or more people affected;

- the declaration of a state of emergency;

- a call for international assistance.

Eight significant flood events in Kenya are recorded in EM-DAT for the period June 2015 to December 2019. From these we remove the Solai earth dam collapse of May 2018 as there were major non-meteorological reasons for its collapse (including lack of maintenance and an outdated design; NECC, 2018). We merge the two entries beginning 14 March 2018 as they relate to the same period of heavy rainfall. This leaves six flood events, to which we add the landslide of November 2019 as this was directly triggered by a period of heavy rainfall. Compared to the KRCS record, the EM-DAT record is much smaller and so precludes a robust quantitative analysis. Instead we consider each event in turn and determine the relevance of the advisories for anticipating these most significant flooding events, for which early warning would have been most valuable.

Finally we conclude by addressing question 4 . Here we determine the number of times an FbF system based on HRAs might be expected to trigger in each county. We assume here that actions have a lifetime as described above and that the system will not be triggered again if an action is still active in that county.

\section{Results}

\subsection{How much rain fell in counties under HRAs?}

We begin by identifying the total area of all counties named in each HRA and compare this with the accumulated rainfall over Kenya during the advisory valid window. For convenience, advisories are labelled (A-Z, followed by $\left.A^{\prime}-G^{\prime}\right)$ in Table 1, and these labels are used from this point.

Figure 3 shows all the advisories and the resultant accumulation. From a visual comparison, we see that 18 advisories provide a good forecast of all areas going on to receive at least $50 \mathrm{~mm}$ rainfall accumulation $(\mathrm{A}, \mathrm{F}, \mathrm{H}, \mathrm{J}, \mathrm{K}, \mathrm{L}, \mathrm{P}, \mathrm{R}, \mathrm{S}$, $\mathrm{Y}, \mathrm{Z}, \mathrm{A}^{\prime}, \mathrm{B}^{\prime}, \mathrm{C}^{\prime}, \mathrm{D}^{\prime}, \mathrm{E}^{\prime}, \mathrm{F}^{\prime}$, and $\left.\mathrm{G}^{\prime}\right)$. For these advisories, preparedness is most likely to have been considered worthy, and local actions based on these advisories are likely to be hits.

Nine advisories do successfully warn of heavy rainfall in some areas whilst failing to warn other counties which received similar amounts (G, I, M, N, O, T, V, W, and X). In these cases preparedness may have been considered worthy, although preparedness would not have reached all those potentially affected by flooding, with risk of missed events and therefore failing to act.

Five advisories warned the "wrong" counties, where more accumulation was seen in unwarned counties than those receiving warnings $(\mathrm{C}, \mathrm{D}, \mathrm{E}, \mathrm{Q}$, and $\mathrm{U})$. One advisory (B) 
(a) Counties warned in each advisory

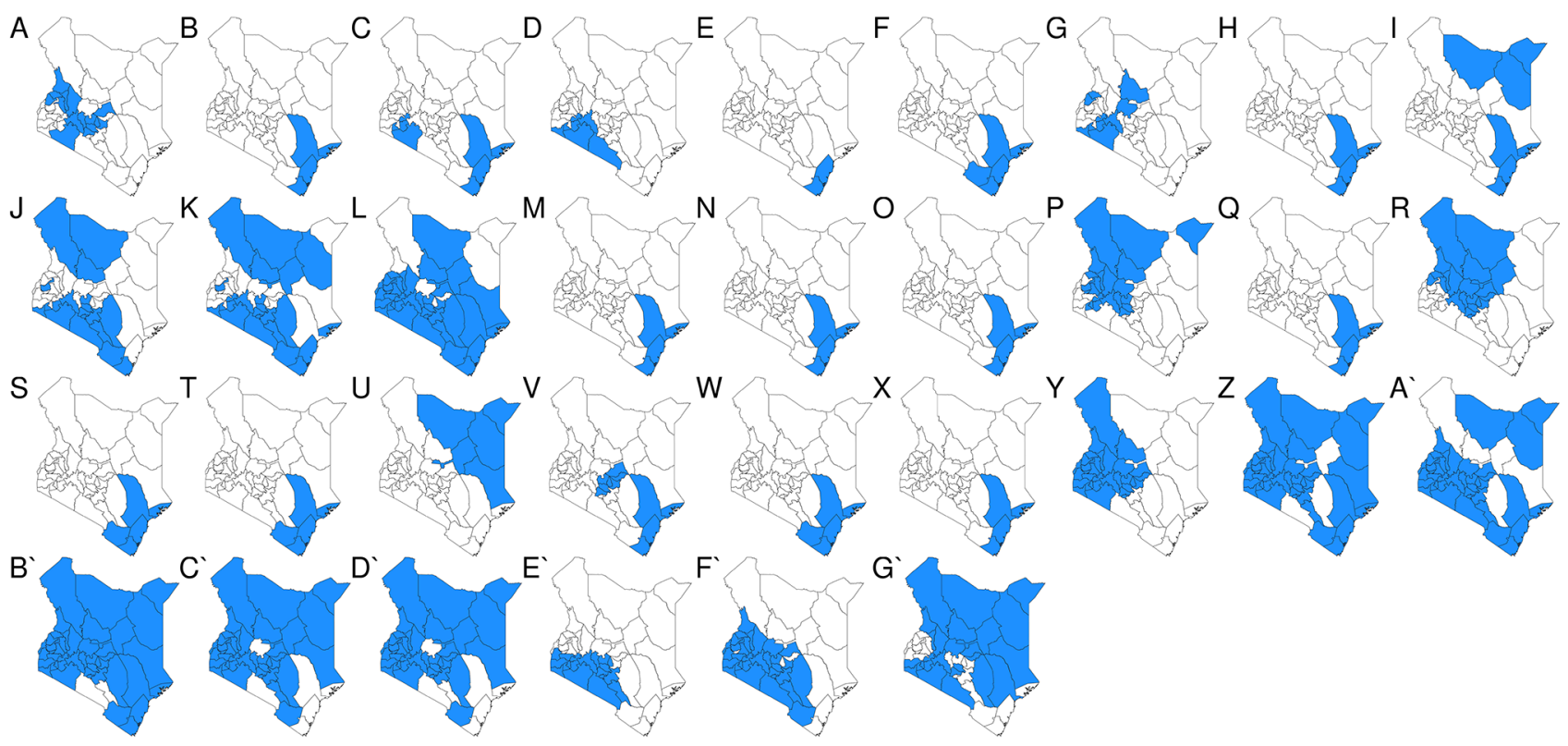

(b) Accumulated rainfall during each advisory window

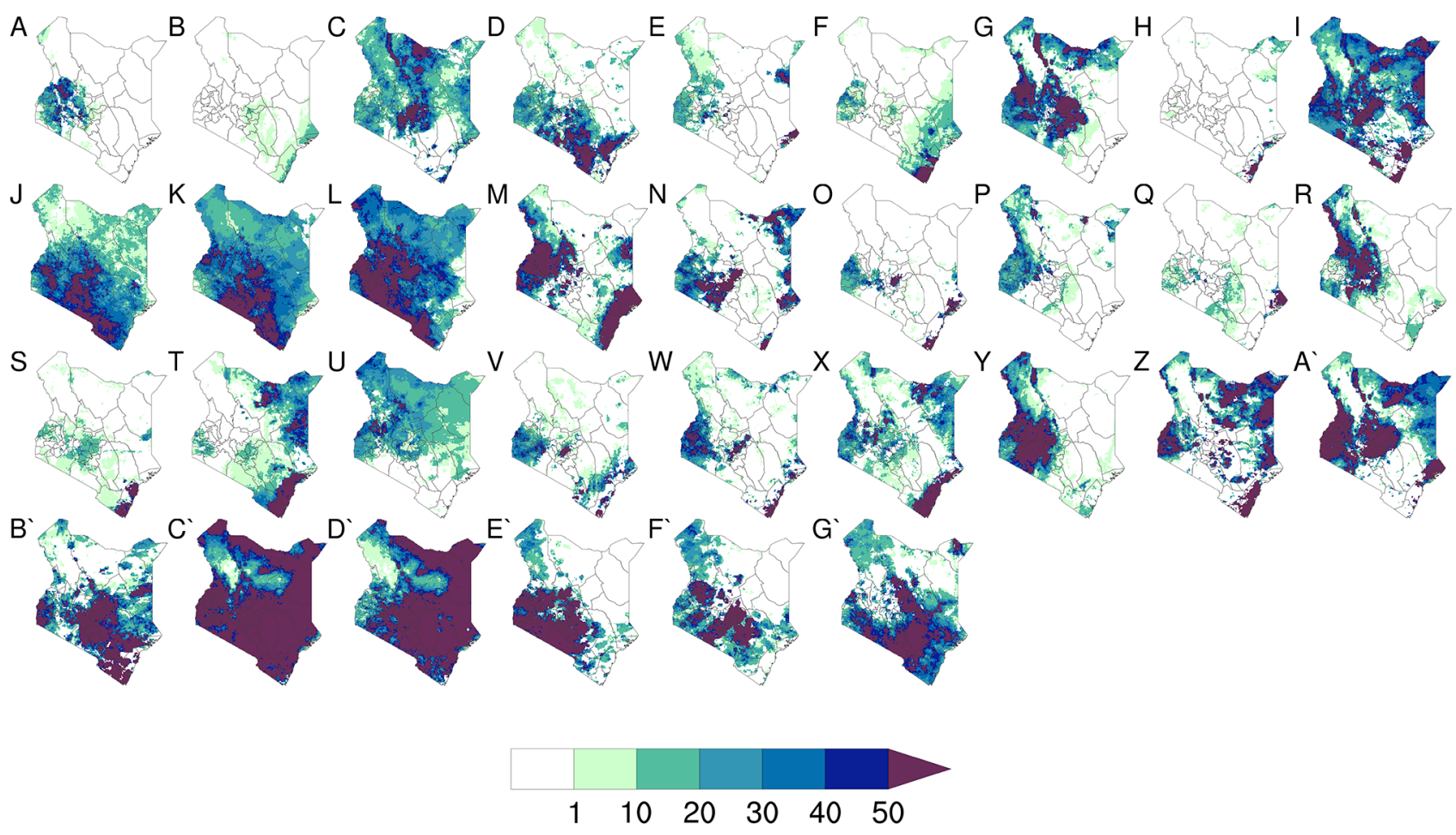

Figure 3. (a) Counties with active warnings for each of the 33 heavy rainfall advisories issued by the KMD during 2015-2019 (advisory details are given in Table 1). (b) Rainfall accumulations (mm) during each advisory window, based on CHIRPS. 


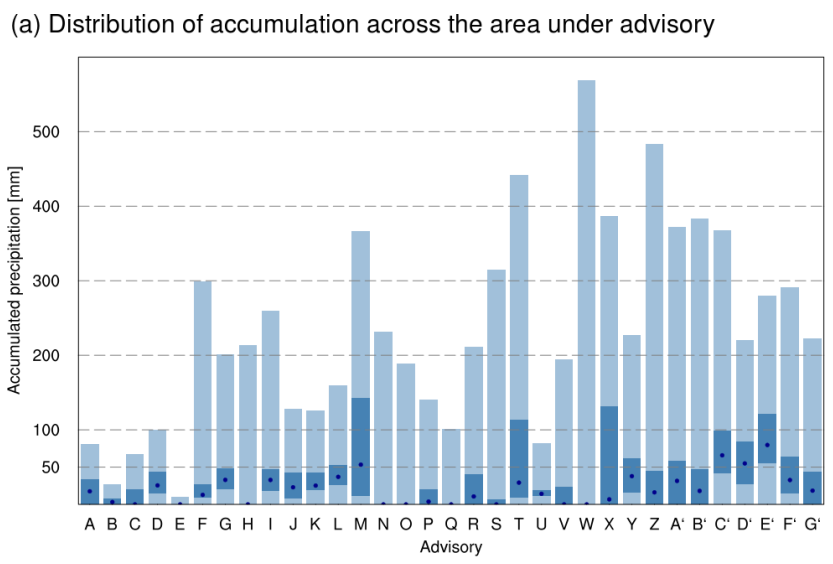

(b) Percentage of advisory area receiving threshold accumulation

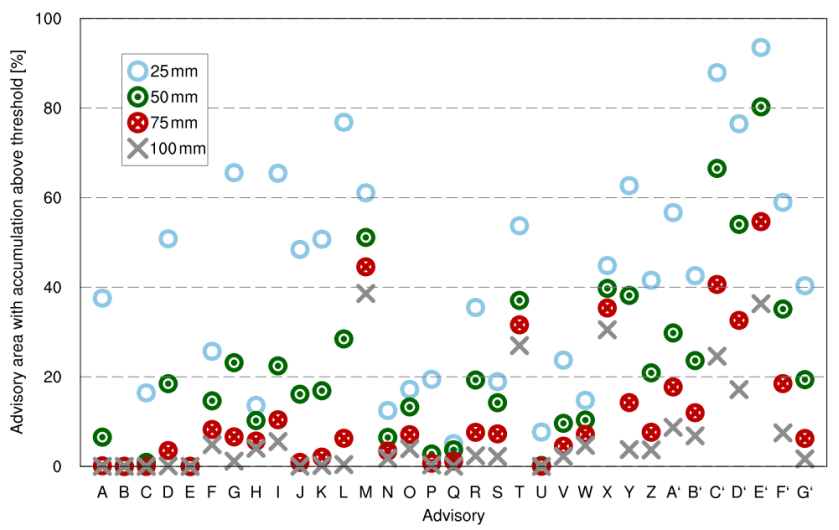

Figure 4. How much rain fell in counties under advisory? (a) Rainfall accumulation during advisory window, showing distribution over all $5 \mathrm{~km}$ square grid points within counties mentioned in advisory (light/dark shading shows the range/interquartile range of the distribution, and the dot indicates the median). (b) Percentage of each advisory region where rainfall accumulation was above 25 , 50,75 , or $100 \mathrm{~mm}$.

warned coastal counties of heavy rain, yet $20 \mathrm{~mm}$ fell during a $2 \mathrm{~d}$ window, a relatively normal amount for the region. For these six advisories it is unlikely that preparedness triggered by the advisories would be considered worthwhile; instead it would possibly be seen as false alarms and misses.

Next, we consider the rainfall distribution across these regions under advisory. Figure 4a shows the rainfall accumulation across the warned region for each advisory, presented as the distribution over the sample of $25 \mathrm{~km}^{2}$ CHIRPS grid points. Figure $4 \mathrm{~b}$ shows the percentage of the warned area which receives rainfall accumulation above thresholds 25 , 50,75 , and $100 \mathrm{~mm}$. We see that for the vast majority of advisories (29 out of 33), less than $50 \%$ of the warned area received over $50 \mathrm{~mm}$. This implies that for any point location falling in an area under advisory, there is generally over a $50 \%$ chance that no "significant" accumulation will be seen. This is inevitable for rainfall early warnings, particularly in a region with a large contribution from localized but intense

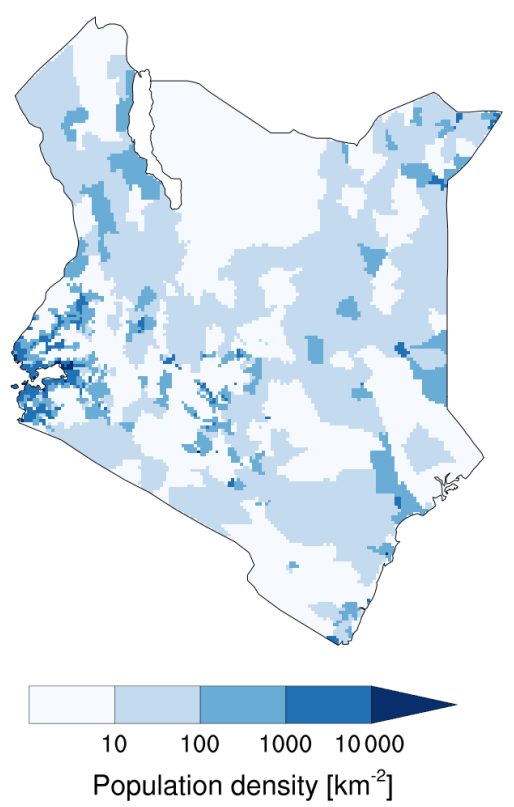

Figure 5. Ward-level density of the population exposed to 1-in-5year flooding, produced by KRCS (see Sect. 2.2.2 for details).

convective storms, leading to high spatial variability in rainfall totals.

From a meteorological perspective then, we find the advisories to be relatively good indications of heavy rainfall. Summarizing the above semi-quantitative analysis of Figs. 3 and 4 , we conclude that 18 successfully warned those regions which did receive heavy rainfall, 9 provide warning for some regions but miss other regions, and only 6 of 33 are unlikely to be useful for early preparedness actions. However at the same time, nearly all "good" advisories warn significantly larger areas compared to the areas which go on to receive heavy rainfall.

We next turn to potential actions triggered by the advisories, estimating the relative extent of preparedness action implied by advisories along with the potential public perception of the actions based on locally experienced rainfall.

\subsection{What is the extent of preparedness action implied by advisories?}

Ward-level density of the population exposed to 1-in-5-year flooding is shown in Fig. 5. High population density is seen around the Lake Victoria basin and elsewhere in the central highlands, although large areas of this highly populated region are not exposed to significant flood risk. This indicates the importance of taking patterns of exposure into account. This population density is then integrated across the warned region for each advisory to estimate the total number of exposed people warned by the advisory. This is shown as the black stars in Fig. 6a. 
(a) Exposed population under advisory receiving threshold accumulation

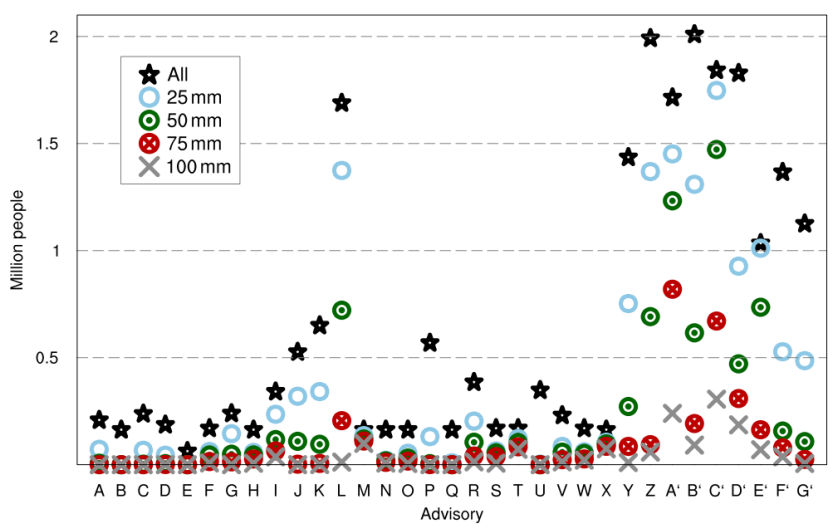

(b) Percentage of exposed and warned population receiving threshold accumulation

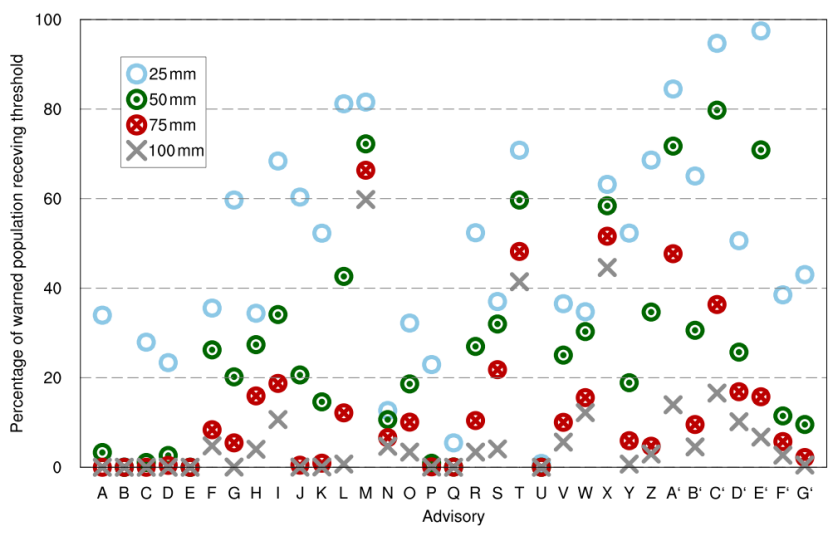

Figure 6. What is the extent of preparedness action implied by advisories? (a) The total population living in the warning region (black star) and the number living in that region also receiving at least 25, 50,75 , or $100 \mathrm{~mm}$ rainfall over the advisory window. (b) Percentage of the population living in the advisory region and also receiving above-threshold rainfall.

There is significant variability in the extent of the warnings for the population at risk from flooding: eight advisories warn areas where at least 1 million people are exposed to flooding. The rest warn around 500000 people and fewer, and of these the warning from 18 advisories is "only" targeted at fewer than 200000 people (these smallest-scale warnings are generally when only warnings for coastal counties are active). This quantifies the significant variations in the extent and cost of preparedness actions which could be linked to the advisories.

To evaluate the extent to which this preparedness would have been perceived as worthwhile, we also show the number of exposed people living in a warned area which then went on to receive accumulation of $25,50,75$, or $100 \mathrm{~mm}$. These results are also shown in Fig. 6a, whilst Fig. $6 \mathrm{~b}$ presents these values as a percentage of the population warned which received rainfall above each threshold. Since these scores are conditioned on exposed population, they are highly sensitive to the underlying exposed population density. They will only be improved if heavy rain falls on an area at risk from flooding, and this improvement will be higher if the area is more densely populated. In this way we move beyond purely meteorological verification and take into account realworld implications of acting on a forecast. This also considers the potential response of beneficiaries of flood preparedness: if flood preparedness is carried out in a region that subsequently receives significant rainfall, most people will see the preparedness as worthwhile. Conversely, people are more likely to see the action as a false alarm if no significant rainfall falls where they live.

Focusing again on $50 \mathrm{~mm}$ accumulation as a nominal threshold for increased flood risk, we see several advisories for which most people receiving early preparedness would not have seen significant rainfall. For eight advisories less than $10 \%$ of those receiving assistance would have seen more than $50 \mathrm{~mm}$; these are unlikely to be seen by most as worthy actions (A-E, P, Q, and U). At the other end of the scale, six advisories see significant accumulation for at least $60 \%$ of those assisted (M, T, X, $\mathrm{A}^{\prime}, \mathrm{C}^{\prime}$, and $\left.\mathrm{E}^{\prime}\right)$. The remaining 24 see significant rainfall for between $10 \%-40 \%$ of those affected. Notably, by this metric the first five advisories (covering mid-2015 to mid-2017) are among the worst-performing, whilst those most likely to have led to worthy actions were all issued in 2018 and 2019.

\subsection{Did advisories warn of flooding?}

We next turn to the verification of the advisories against recorded flooding in the KRCS flood record. HR and precision are shown in Fig. 7. This shows a clear improvement of the advisories over time: for advisories in 2015 and 2016 less than $5 \%$ of flood events were hit, even with a favourable assumption of a $30 \mathrm{~d}$ lifetime of preparedness actions. Conversely action on advisories in 2019 would have seen a $40 \%$ HR with a $0 \mathrm{~d}$ lead time, rising to $60 \%$ or over $70 \%$ if actions are taken with a 1- or 2-week lifetime. Though 2019 also saw many more advisories issued compared to earlier years, each was also more precise, with a $40 \%$ chance of seeing flooding in a county within 2 weeks of taking action during 2018 and 2019 , compared with $20 \%$ in $2017,10 \%$ in 2016 , and $0 \%$ in 2015.

Though recent advisories perform well when measured against the KRCS record of flooding, it may not be that all events in the record would have required significant preparedness. We therefore turn now to the seven most significant flooding events in Kenya over the period, recorded in the EM-DAT database. These are compared with relevant advisories; for simplicity we consider an advisory to be relevant if it was issued in the $7 \mathrm{~d}$ preceding the indicated start date of the impact as early preparation triggered by that advisory would have been in place for the onset of the event. We do not require the heavy rainfall window to explicitly overlap with the recorded period of impact, allowing for some lag between heavy rain and flooding. The locations and details of 


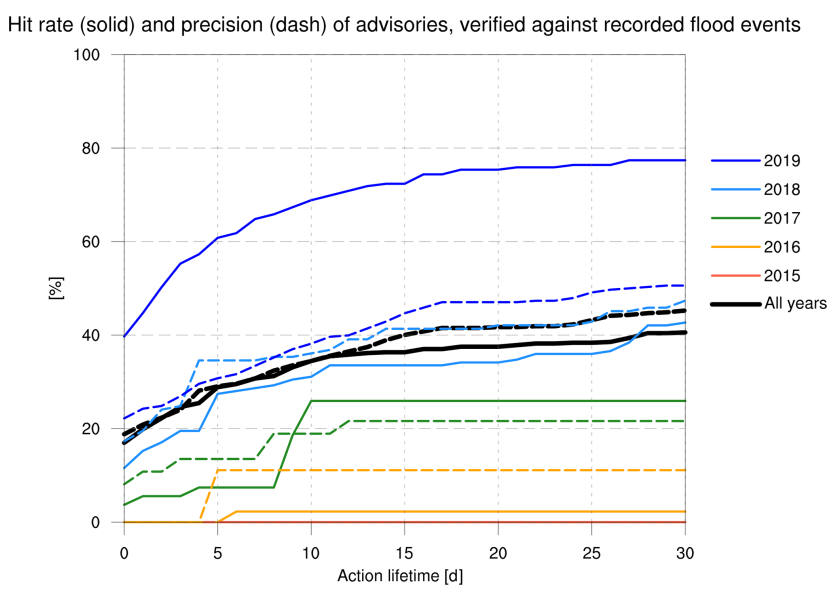

Figure 7. Skill statistics of the advisories when verified against observed flood events at county level. The hit rate shows the percentage of events which were preceded by an advisory in that county (solid line), whilst the precision shows the percentage of county warnings which were followed by an event (dashed line; note that precision is equivalent to $100 \%$ minus the false-alarm ratio). Statistics are calculated for all years (black line) and each year separately (coloured lines) across a range of "action lifetimes", such that theoretical action based on each advisory is assumed to have a lifetime so is still considered a "hit" as long as the flood event occurs within the lifetime of the action.

the events are plotted in Fig. 8, which also shows the counties mentioned in any relevant advisories as defined above (if any). These seven events are now discussed in turn.

Figure 8a shows the significant flooding which occurred across Kenya in December 2015 during the large 2015 El Niño event that peaked in December. This event led to the highest number of deaths recorded in the sample (112). No HRA was issued at any point before or during this event or during the season as a whole. Notably, seasonal forecasts did indicate an increased risk of a particularly wet season, although as a whole the seasonal rainfall anomalies were smaller than previous comparable El Niño events (Siderius et al., 2018; MacLeod and Caminade, 2019).

Figure $8 \mathrm{~b}$ represents a smaller event in Turkana county caused by intense rainfall on a single afternoon (10 March 2016). This rainfall led to river overflow, three deaths, displacement of 1000 people, and loss of livestock. No HRA was issued for this event.

The third event (Fig. 8c) occurred at the end of April 2016. This flooding impacted over 10000 people across semi-arid counties in the north (Turkana, Marsabit, and Wajir) along with Nairobi. In Nairobi the rainfall triggered the collapse of a building in the Huruma estate (a building which was not constructed to safe standards), ultimately leading to 52 deaths. In advance of this period, an HRA was issued by the KMD (advisory C); however warnings were given for coastal counties and parts of western Kenya but not for those counties most seriously impacted. The KRCS did trigger an early response based on this advisory, activating response teams and sending out warnings via SMS to communities living in lowland areas. Although no heavy rainfall was directly experienced in those regions for which the response was triggered, the action was felt to be worthwhile at the KRCS as some flooding was experienced later due to the Tana River bursting its banks after heavy rainfall in the central highlands.

The next EM-DAT event occurred in May 2017 (Fig. 8d). This involved coastal counties along with some in the central highlands and some in the west. A total of 26 deaths were recorded, with over 25000 affected for this event, during which a reported $235 \mathrm{~mm}$ of rain fell on Mombasa in a $24 \mathrm{~h}$ period between 8-9 May. Although an advisory for coastal counties was issued in late April (advisory E), the valid period was a single day which saw little accumulation in the warned counties.

Figure 8e shows the impacts of heavy rainfall during the 2018 long rains season, which has been evaluated in depth elsewhere (Kilavi et al., 2018; Finney et al., 2019). Widespread flood impacts were seen across the country beginning on 14 March and extending throughout the month. Two advisories were issued during March (advisories $\mathrm{K}$ and L). The first was issued on the 9 March and covered the period 13-15 March, and a follow-up was issued on 15 March, covering the period 16-19 March. Both of these periods saw significant rainfall accumulation (see Fig. 3 and Kilavi et al., 2018). Every county noted in EM-DAT as experiencing flood impacts was mentioned in these advisories except for Mandera in the extreme north-east of Kenya.

Figure 8f shows impacts that occurred from 17-24 October during the short rains 2019. Flash floods, landslides, and riverine floods were reported in Turkana, Wajir, and ElgeyoMarakwet counties. Two advisories were issued preceding this event (advisories $\mathrm{Z}$ and $\mathrm{A}^{\prime}$ ). The first was issued on 10 October, covering the period 10-14 October, and a second was issued on 14 October, covering the period 16-20 October. Counties with reported flood impacts were all mentioned in these HRAs.

The final event in the sample also occurred during the 2019 short rains: a landslide in West Pokot on 23 November (Fig. 8g). This occurred following heavy rainfall across many counties, for which a warning was issued several days ahead of the event, on 18 November, covering 19-24 November (advisory $\mathrm{C}^{\prime}$ ).

In summary the first four events in the study period were not well warned by advisories. The third event in April 2016 was preceded by a warning, but it did not target the counties with significant flood impacts. The final three events in 2018 and 2019 were all preceded by advisories correctly targeting the counties which saw major impacts from heavy rainfall; the lead time between the first advisory and the recorded start of the impacts for these three events was 5, 7, and $5 \mathrm{~d}$, respectively. Advisories issued in 2018-2019 therefore gave effective warning to areas experiencing significant flooding impacts, whilst the earlier advisories did not. Along with skill 

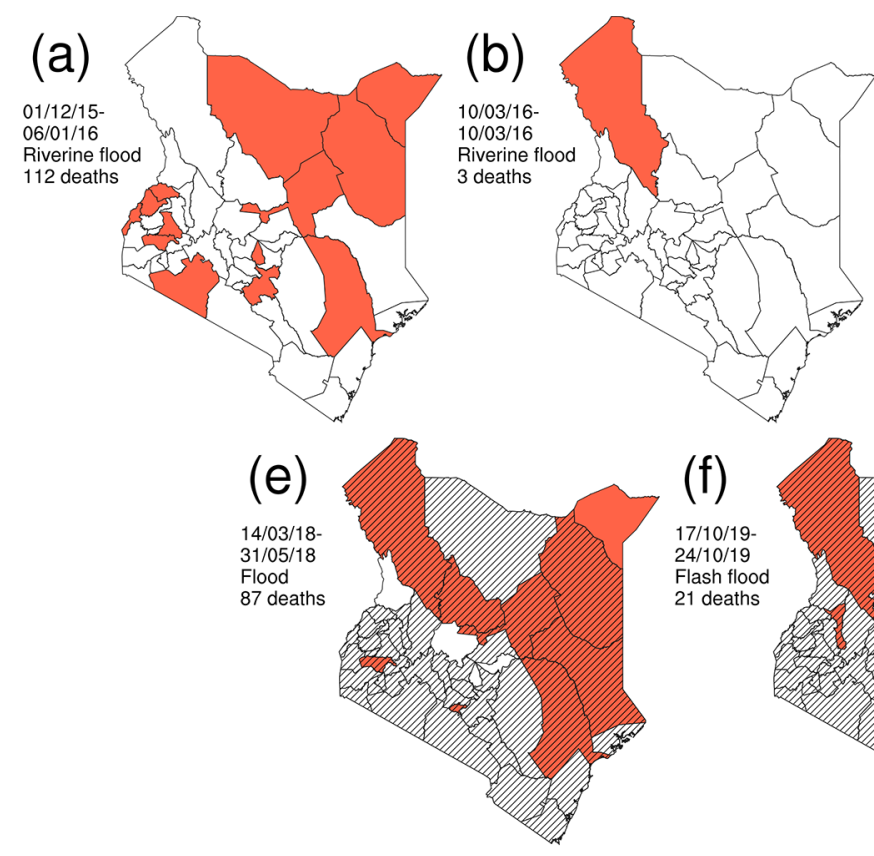

Impacts recorded in EM-DAT

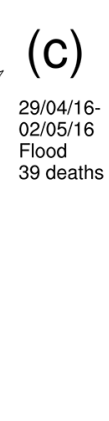

(f)

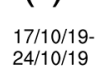
$17 / 10 / 19-$
$24 / 10 / 19$ $24 / 10 / 19$
Flash flood Flash flood
21 deaths
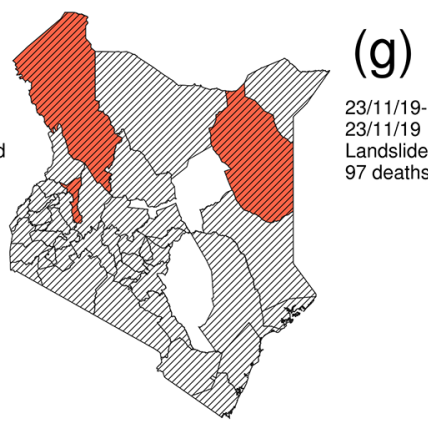
23/11/1923/11/19 Landslide
97 deaths

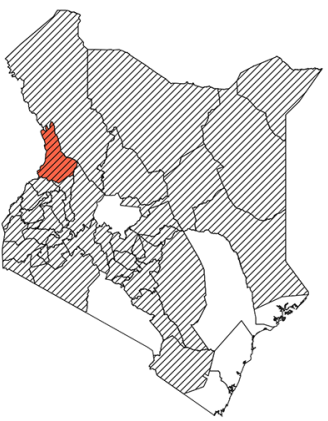

(d)

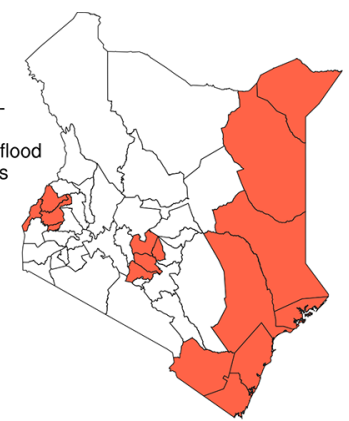

Figure 8. Were the most significant impacts of heavy rainfall preceded by advisories? All seven relevant events extracted from EM-DAT across the advisory period (see Sect. 2.3 for details of event selection). Counties reporting impacts are shown in orange, whilst hatching indicates counties for which warnings were active when the impact was recorded to have begun.

analysis shown in Fig. 7, this suggests that in recent years advisories have improved and have the potential to act as a trigger for an $\mathrm{FbF}$ system. However it should be recalled that the warned area is often much larger than the area experiencing heavy rainfall (see Figs. 4, 6, and 8). Even those advisories where triggering leads to worthy action where impacts are felt will also simultaneously trigger action in many places which do not require early preparedness, and these "actions in vain" may be quite expensive in highly populated regions such as western Kenya. In the next and final section, we turn to a practical consideration of basing such a system on advisories and estimate how often such a system might be expected to trigger.

\subsection{How often would an FbF system based on advisories trigger?}

An important consideration in setting up an $\mathrm{FbF}$ system is how frequently it can be expected to be activated. It is desirable to prepare for all significant events; however more frequent triggering limits the cost of actions if the system is to remain financially sustainable. Here we estimate how often such a system might trigger.

Naturally the number of advisories will fluctuate year to year depending on climate variability. However 2018 and 2019 could reasonably indicate the potential number of activations of an FbF system, given that they both experienced significant rainy seasons (with 11 advisories issued in 2018 and 13 in 2019; Fig. 2a). For low-cost actions such as targeted communication of the warning to vulnerable communities, this may be an acceptable number of triggers, and results from Sect. 3.3 suggest that these would successfully warn against all significant flood events. A key requirement of the advisories is to warn the vulnerable public of significant hazards, and so for this purpose the frequency of issuance is appropriate to the cost of the warning.

In the FbF context the advisories could be used to instigate actions from response organizations and disaster management. Several actions have already been identified as potentially forming part of an EAP (Maurine Ambani, personal communication, 2020):

- strengthening of barriers designed to prevent people from crossing rivers or places where there is usually fast-flowing water;

- provision of water containers and water treatment;

- provision of vouchers to affected populations to access water treatment tablets, containers, and treated mosquito nets.

These kinds of actions would have significant costs, and so more than 10 triggers in a year may not be realistic. However on the other hand, triggering on every advisory may not be necessary. Frequently an advisory is issued which follows on from another, describing a continuing rainfall event (e.g. J-L, 


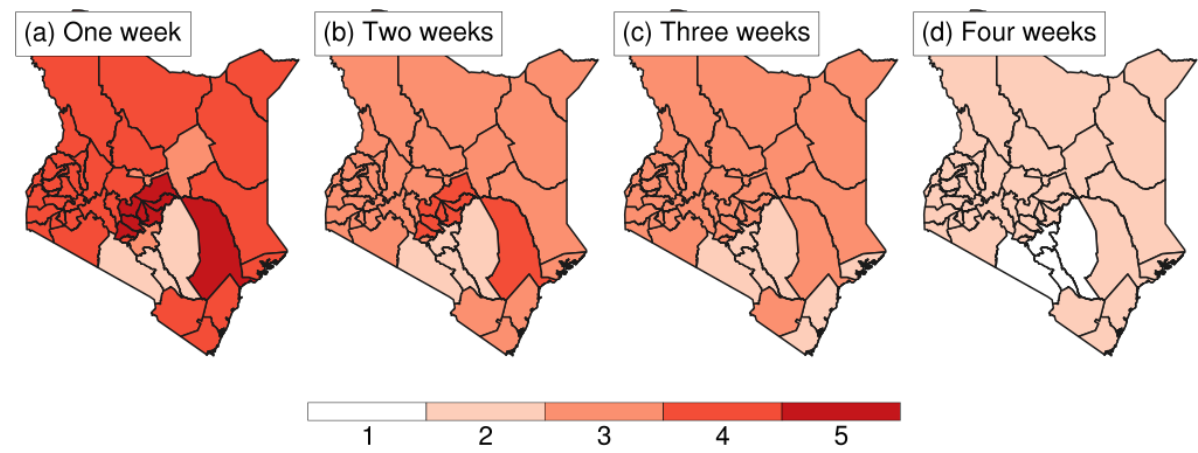

Figure 9. How many times per year might an FbF system based on advisories trigger? The number of potential triggers per county during 2019: here we assume that an action is triggered if an advisory is issued as long as no action had already been triggered in the preceding 1, 2,3 , or 4 weeks (a-d).

$\left.\mathrm{M}-\mathrm{O}, \mathrm{C}^{\prime}-\mathrm{G}^{\prime}\right)$. Significant flood preparedness may not need to be carried out for each individual one of the advisories in sequence as actions of this nature will have a "lifetime" that may span the interval between several consecutive issued warnings (Coughlan de Perez et al., 2016). For example river defences will still be effective several weeks after action is taken to repair or reinforce them.

The impact of action lifetime on trigger frequency is illustrated for each county in 2019 in Fig. 9. Here we assume that the action will not be repeated if another advisory follows closely after the action is triggered. The number of total actions is shown, assuming an action lifetime of $1,2,3$, or 4 weeks. We consider multiple chained advisories such as $\mathrm{C}^{\prime}-$ $\mathrm{G}^{\prime}$ as triggering a single preparedness action: after the first days of heavy rain, activity will have already moved from preparedness to response mode; additional advisories may trigger scaling-up of existing response operations.

With an action lifetime of 1 week most counties would have triggered 4 times in 2019. With a longer lifetime the system activates less often, and in the longest case of 4 weeks no county would have activated in 2019 more than twice (on average, once for each of the rainy seasons).

Typical $\mathrm{FbF}$ approaches tend to focus on extreme events rather than floods which occur every year (RCRCCC, 2020), and so even taking into account long action lifetimes, this trigger frequency may still be too high for high-cost actions. However this frequency may yet be appropriate for $\mathrm{FbF}$ linked to low-cost, low-regret actions, such as fast-tracking drainage clearance which has already been planned and budgeted for.

\section{Discussion and recommendations}

Here we have evaluated the KMD HRAs. This has been done from the perspective of a humanitarian agency such as the KRCS as if the advisories were used to initiate a preparedness protocol such as FbF in order to reduce risks related to heavy rainfall. Such EAPs for a national flood FbF system are currently being developed. Our assessment of the advisories has considered the following:

- the relationship between area warned and the subsequent rainfall received;

- the scale of preparedness triggered by the advisories and the perception of the actions based on locally experienced rainfall;

- whether the most significant recent flood events followed HRAs;

- how frequently an FbF system could be expected to trigger.

We now draw some general conclusions and provide some recommendations for improvement of the HRAs and outline the development of flood risk forecasting in Kenya.

\subsection{Conclusions}

Advisories issued in the "early period" (from the first in 2015 up to and including 2017) do not appear to be particularly effective for preparedness for flood or heavy rain impacts. For each of the nine advisories that were issued in this early period, the counties which were warned did not generally receive significant amounts of rainfall. Furthermore four significant flood events were reported in this period, and none were anticipated by any advisory, whilst $0 \%, 5 \%$, and less than $20 \%$ of all recorded flooding of any magnitude was preceded by advisories in each event of 2015-2017, respectively. We conclude then that it is unlikely that conducting preparedness actions based on advisories between 20152017 would have effectively reduced flood or heavy rain impacts.

However we note evidence of an improvement in the potential utility of advisories in recent years of 2018 and 2019 , when they were more frequently issued. Notably, these years had particularly wet seasons: March-May 2018 and 
October-December 2019. For a 2-week action lifetime, preparedness at county level based on advisories in 2018 and 2019 would have anticipated $40 \%$ and $70 \%$ of all 363 recorded county-level flooding events in these years, whilst the three periods which saw significant mortality were directly associated with heavy rainfall which was well warned by advisories. We conclude then that advisories issued across 2018/19 were particularly skilful at anticipating heavy rainfall and that preparedness actions based on these could have led to reductions in the impacts of the worst floods in this period. If the performance of advisories over this period is indicative of future performance, then they have the potential to effectively anticipate significant flooding impacts in Kenya.

One factor for the improved hit rate in 2018 and 2019 may be the higher frequency of issuance. However this does not explain the fact that infrequent early advisories were not generally followed by significant rainfall as noted above. This poor performance in the early period might instead be related to the novelty of the system. The first advisories were issued in 2015, and it may have taken some time to develop the systems and expertise and gain confidence in issuing advisories. Another explanation for the change in skill is the evolving access to forecast information from global models at the KMD.

In mid-2016 the KMD was granted a 2-year trial license to ECMWF "eccharts" through the SWFDP, which is reported to have been crucial in informing the advisories released during that period (Mary Kilavi, personal communication, 2020) and particularly so during the long rains 2018 (advisories J-Q). In addition the GHM in use since August 2017 has provided a multi-model, easy-to-interpret visualization of potential severe weather. Evaluation has shown that multi-model forecasts outperform individual models for extreme precipitation (Robbins and Titley, 2018). The availability of a higher-skill, multi-model forecast at the KMD in an easy-to-interpret format may then be a factor in the significant improvement in skill of advisories during 2018 and 2019. Indeed it is reported that the GHM was a key source of information for the advisories which were issued in advance of all three significant heavy rainfall impacts reported during 2018 and 2019 (Fig. 8e-g; see also Kilavi et al., 2018, for skill analysis of the GHM forecasts used during the 2018 "long rains").

Overall we demonstrate here in the first systematic verification conducted of the HRAs that they have skill. We find an increase in skill over time and that the HRAs anticipated the most significant flood events during 2018 and 2019. However we also find they lack spatial precision on the precise location of heavy rainfall impacts, which may limit their use as a trigger in KRCS EAPs.

\subsection{Recommendations}

Though the HRAs have skill, their likely utility will clearly depend on the specific context of use. In order to fully ascertain appropriate actions which could be triggered by the HRAs, an econometric analysis of the costs and avoided losses of a range of preparedness actions is necessary (and recommended). We note here however that their intended purpose is to alert county governments, other agencies, and the general public of the possibility of heavy rainfall. For this purpose they are effective: they are widely disseminated; the text identification of counties under advisory requires no technical knowledge to understand; and most importantly, they have skill. Indeed, Kilavi et al. (2018) note dissemination and use of HRAs during the long rains 2018.

As a source of information for a systematic FbF system for flooding, the advisories have several useful characteristics for the KRCS: they are produced by the national mandated agency for weather forecasting; they are readily available at no cost; and being text-based, they require no specific knowledge for interpretation. However it is likely that they are not suitable for triggering a KRCS EAP for flooding. The county-scale warning limits the spatial precision of interventions, and the frequency of the triggering per county is likely to be too high for FbF, which is intended to target extreme events with a return period of 1 in 5 years or greater. In addition the HRAs only provide a general picture of potential flood impacts without taking into account any local hydrological conditions. However given the clear skill of HRAs found here, there is clear scope of the KMD to develop these in the context of impact-based forecasting (WMO, 2015): here we make some recommendations for improving the HRAs and the flood forecasting from the perspective of stakeholders such as the KRCS.

\subsubsection{Developing the HRAs}

Improvement of the probabilistic information in the HRAs would make them more fit for the purpose of FbF. A single category $33 \%-66 \%$ is issued in nearly all advisories, which limits options for preparedness actions. More diverse and precise probabilities would allow a range of increasing levels of preparedness activities, where high-cost actions are only triggered for the highest probabilities. Of course it is essential that these probabilities are reliable, and a relatively low frequency of subjectively developed forecasts makes this aspect of the forecast difficult to evaluate. However the use of historical forecasts and hindcasts from ensemble forecasting systems used in the GHM (Robbins and Titley, 2018) currently in use at the KMD would help to establish the reliability of probabilities and provide a scientific basis for issuing more specific heavy rainfall probability forecasts. Analysis of these dynamical models should also evaluate their performance for the four flooding events in the early period of the 
KMD advisories (Fig. 8a-d) to see if these systems did capture these events.

The heavy rain warning area could also be more precise by providing it as a free shape rather than administrative county boundaries. Whilst naming counties in the advisory is essential for communication to the public and to county government disaster risk management structures, the precise area of heavy rainfall areas will not align with administrative boundaries, and so warning whole counties will tend to overestimate the total area expected to experience rainfall. Such warning polygons are generated by the GHM, and forecasts could be based upon this. The KRCS could then overlay these with maps of population exposure and vulnerability to flood risk in order to further narrow down targets for intervention. This would then provide the building blocks of an impact-based forecasting system following WMO guidelines (WMO, 2015).

Finally many preparedness actions are limited by the lead time of the HRAs. They are often issued in the morning of or the day before the expected start to the rainfall, leaving a small window to coordinate and implement preparedness. A longer-lead heavy rainfall forecast would extend the scope of preparedness actions. Currently the time afforded by existing 7 and $5 \mathrm{~d}$ forecasts from the KMD could be used by the KRCS to prepare higher-cost actions, which are finally triggered upon the issuance of an HRA for the next few days. This approach would be analogous to the ready-set-go approach of the Red Cross designed to integrate seasonal forecasts into decision-making, adapted to a much shorter overall anticipation window (Bazo et al., 2019).

However the provision of forecasts at an even longer lead time could further enlarge the window for preparedness. For instance, sub-seasonal forecasts have been shown to have skill out to several weeks ahead (Vitart et al., 2017), and there is clear potential for warnings on this timescale to inform humanitarian preparedness (White et al., 2017). Evaluation of these timescales is being carried out as part of the ForPAc project, which has identified potential utility over Kenya, and these sub-seasonal forecasts are currently being trialled at the KMD after being made available in real time as part of phase 2 of the S2S project (Kilavi et al., 2018; MacLeod et al., 2020). The longer lead time of these rainfall forecasts can afford the KRCS more flexibility and potential for early preparedness.

Having made these suggestions for the HRAs, we must acknowledge the importance of balancing detail with wide interpretability. In this case, although users such as the KRCS may prefer to see more spatial detail in the advisories, in their current form the text-based, county-level format means that no technical knowledge is required to correctly interpret the information. This facilitates understanding and easy dissemination (e.g. through radio, translation to local languages, and in-person broadcasts to communities). To add additional information may limit the ease with which they are disseminated and their interpretability and accessibility. Ensuring an optimal balance for all stakeholders is a challenge for the KMD and indeed for the NMHSs in general.

\subsubsection{Improving flood forecasting}

Explicit modelling of local hydrology is necessary to provide accurate forecasts of flood risk rather than reliance on rainfall forecasts alone. Although here we do find that HRAs warn of the most significant flooding events (consistent with the analysis of Robbins and Titley, 2018, who also find a good relationship between precipitation forecasts and heavy impacts across the globe), it is unlikely that flood impacts will always be felt after heavy rainfall. Or indeed it is not the case that heavy rainfall is always necessary to trigger flood impacts, which can occur with "normal" rainfall if the soil is already saturated (MacLeod et al., 2020). Accurate characterization of flood impacts requires consideration of nonmeteorological and non-hydrological factors.

A unified national flood modelling and forecasting system would provide the KRCS with a standardized view of flood risk across the country; however the KMD does not yet have such a system, and different approaches are being followed in different basins. The Nzoia basin of western Kenya currently has the only operational flood forecast, where a basin-scale hydrological model is used to generate a $3 \mathrm{~d}$ discharge forecast using basin-average rainfall and soil moisture observations along with a short-range rainfall forecast. Substantial new investment is being made in flood forecasting in Kenya, notably under the World Bank-supported Water Security and Climate Resilience project. This will both upgrade the Nzoia flood-forecasting system with a new hydrological model software and will support an extension of river flood early-warning systems to other main river basins of Kenya, including upgraded hydro-meteorological observation networks supporting hydrological flood forecast models. This will help to provide more targeted relevant flood forecasts, and as the hydrological monitoring network is expanded, this will help to evaluate the background level of flood risk, supported by new hydrological model simulations. The work will also help to strengthen institutional links between the KMD, with the mandate for forecasting in Kenya, and the Water Resource Authority (WRA), with the mandate for flood risk mapping; close collaboration between the KMD and the WRA is essential to ensuring effective and coherent flood risk management and forecasting in the region. Other parallel related activities include the SHEAR HiPac project, which for the Nzoia River basin will map inundation risk in high resolution and link this to forecasts from the existing system, and the EU-supported ECHO project developing flood risk assessment and forecasting for the Tana River.

In the absence of readily available flood forecast information from the NMHSs covering the entire country, some national Red Cross societies are now considering the use of ECMWF GloFAS flood forecasts (see Alfieri et al. (2013), and http://www.globalfloods.eu, last access: 11 Jan- 
uary 2021) to trigger flood EAPs. In Kenya GloFAS may be an appropriate product, whilst the basin-scale flood forecasting remains under development, and there remains no unified national flood-forecasting system. Whilst GloFAS is advantageous as it is freely available with national coverage, the GloFAS forecasts are unable to take advantage of realtime local hydrological observations to initialize the model, limiting the forecast skill. A locally calibrated model which assimilates initial hydrological states would likely provide the optimal basin-scale flood risk forecast. In addition the need for GloFAS forecast verification remains outstanding for most basins. The KRCS should work with relevant organizations to undertake this analysis. Further, use of GloFAS should be sensitive to issues of national ownership of warnings systems.

Ultimately the evaluation of HRAs presented here should be put in the context of flood preparedness systems such as the KRCS flood hazard EAPs. It points to the need, now widely recognized, for strengthened co-production of forecast information and products which support the effective uptake of forecasts into risk management systems. In Kenya, recent projects exemplify this approach, including ForPAc, WISER (Weather and Climate Information Services for Africa) SCIPEA (Strengthening Climate Information Partnerships - East Africa), and W2-SIP (WISER support to ICPAC). Simultaneously, the national early warningearly action platform convened by the KRCS in September 2019 brought together relevant national actors. Coordinated verification of existing forecast products such as the HRAs presented here will help to integrate these into systematic preparedness activities. Whilst in this case the current form of the HRAs may preclude their use as a trigger for the KRCS EAPs, they are able to effectively warn of heavy rainfall and should therefore take a key role in a seamless approach toward mitigating the risk from risks associated with heavy rainfall across Kenya.

Data availability. Digitized advisories have been made available at https://doi.org/10.6084/m9.figshare.13553651.v1 (MacLeod et al., 2021). KRCS flood and exposure data may be shared and given by KRCS. Please contact the lead author for details. CHIRPS and EMDAT rainfall data are freely available by following the relevant citations.

Author contributions. All authors collaborated on the development of the verification strategy and contributed to the paper. MK, EM, and DM digitized the advisories, EM provided the KRCS flood record, MO prepared exposure data, and PR extracted flood impact data from EM-DAT. DM coordinated the study, carried out the analysis, and wrote the text.

Competing interests. The authors declare that they have no conflict of interest.
Acknowledgements. The authors would like to thank the two anonymous reviewers for their suggestions, which led to strengthening of the analysis. In addition the authors would like to thank the KMD for provision of past heavy rainfall advisories and the KRCS for sharing their record of flood events and estimations of floodexposed population.

Financial support. This research has been supported by the Natural Environment Research Council, Economic and Social Research Council, and the UK Department for International Development under the Science for Humanitarian Emergencies and Resilience (SHEAR) programme (grant nos. NE/P000673/1, NE/P000568/1, NE/P000428/1, and NE/P000444/1). Further support for author Maurine Ambani came from the Innovative Approaches for Risk Protection (IARP) project funded by the IKEA Foundation.

Review statement. This paper was edited by Joaquim G. Pinto and reviewed by two anonymous referees.

\section{References}

Alfieri, L., Burek, P., Dutra, E., Krzeminski, B., Muraro, D., Thielen, J., and Pappenberger, F.: GloFAS - global ensemble streamflow forecasting and flood early warning, Hydrol. Earth Syst. Sci., 17, 1161-1175, https://doi.org/10.5194/hess-17-1161-2013, 2013.

Amoako, C. and Frimpong Boamah, E.: The three-dimensional causes of flooding in Accra, Ghana, Int. J. Urban Sustain. Dev., 7, 109-129, 2015.

Bazo, J., Singh, R., Destrooper, M., and de Perez, E. C.: Pilot Experiences in Using Seamless Forecasts for Early Action: The "Ready-Set-Go!" Approach in the Red Cross, in: Sub-Seasonal to Seasonal Prediction, Elsevier, 387-398, available at: https: //www.elsevier.com/books/sub-seasonal-to-seasonal-prediction/ robertson/978-0-12-811714-9 (last access: 11 January 2021), 2019.

Beck, H. E., Vergopolan, N., Pan, M., Levizzani, V., van Dijk, A. I. J. M., Weedon, G. P., Brocca, L., Pappenberger, F., Huffman, G. J., and Wood, E. F.: Global-scale evaluation of 22 precipitation datasets using gauge observations and hydrological modeling, Hydrol. Earth Syst. Sci., 21, 6201-6217, https://doi.org/10.5194/hess-21-6201-2017, 2017.

Berghuijs, W. R., Harrigan, S., Molnar, P., Slater, L. J., and Kirchner, J. W.: The relative importance of different flood-generating mechanisms across Europe, Water Resour. Res., 55, 4582-4593, 2019.

Coughlan de Perez, E., van den Hurk, B., van Aalst, M. K., Amuron, I., Bamanya, D., Hauser, T., Jongma, B., Lopez, A., Mason, S., Mendler de Suarez, J., Pappenberger, F., Rueth, A., Stephens, E., Suarez, P., Wagemaker, J., and Zsoter, E.: Action-based flood forecasting for triggering humanitarian action, Hydrol. Earth Syst. Sci., 20, 3549-3560, https://doi.org/10.5194/hess-20-35492016, 2016.

Dinku, T., Funk, C., Peterson, P., Maidment, R., Tadesse, T., Gadain, H., and Ceccato, P.: Validation of the CHIRPS satellite 
rainfall estimates over eastern Africa, Q. J. Roy. Meteorol. Soc., 144, 292-312, 2018.

EM-DAT: The Emergency Events Database - Université catholique de Louvain (UCL) - CRED, available at: http://www.emdat.be, last access: 27 November 2020.

Finney, D. L., Marsham, J. H., Walker, D. P., Birch, C. E., Woodhams, B. J., Jackson, L. S., and Hardy, S.: The effect of westerlies on east african rainfall and the associated role of tropical cyclones and the madden-julian oscillation, Q. J. Roy. Meteorol. Soc., 146, 647-664, https://doi.org/10.1002/qj.3698, 2019.

Funk, C., Peterson, P., Landsfeld, M., Pedreros, D., Verdin, J., Shukla, S., Husak, G., Rowland, J., Harrison, L., Hoell, A., and Michaelsen, J.: The climate hazards infrared precipitation with stations - a new environmental record for monitoring extremes, Sci. Data, 2, 1-21, 2015.

Gros, C., Bailey, M., Schwager, S., Hassan, A., Zingg, R., Uddin, M. M., Shahjahan, M., Islam, H., Lux, S., Jaime, C., and Coughlan de Perez, E.: Household-level effects of providing forecast-based cash in anticipation of extreme weather events: Quasi-experimental evidence from humanitarian interventions in the 2017 floods in Bangladesh, Int. J. Disast. Risk Reduct., 41, 101275, https://doi.org/10.1016/j.ijdrr.2019.101275, 2019.

Kilavi, M., MacLeod, D., Ambani, M., Robbins, J., Dankers, R., Graham, R., Titley, H., Salih, A. A., and Todd, M. C.: Extreme rainfall and flooding over central Kenya including Nairobi city during the long-rains season 2018: causes, predictability, and potential for early warning and actions, Atmosphere, 9, 472, https://doi.org/10.3390/atmos9120472, 2018.

MacLeod, D., Mwangi, E., and Kilavi, M.: Digitized heavy rainfall advisories 2015-2019, figshare, Dataset, https://doi.org/10.6084/m9.figshare.13553651.v2, 2021.

MacLeod, D. and Caminade, C.: The moderate impact of the 2015 El Niño over East Africa and its representation in seasonal reforecasts, J. Climate, 32, 7989-8001, 2019.

MacLeod, D., Dankers, R., Guigma, K., Graham, R., Jenkins, L., Kilavi, M., Kiptum, A., Mwangi, E., Njogu, A., and Todd, M.: Drivers and subseasonal predictability of heavy rainfall in equatorial East Africa and relationship with flood risk, J. Hydrometeorol., accepted, 2020.

NECC: Solai Dam Report, 12 November 2018, Tech. rep., National Environmental Complaints Committee, available at: https: //perma.cc/66E4-R9L2 (last access: 11 January 2021), 2018.

OCHA: Flash Update 6: Floods in Kenya 7th June 2018, Tech. rep., UN Office for the Coordination of Humanitarian Affairs, available at: https://perma.cc/B47A-HSYF (last access: 11 January 2021), 2018.

Powers, D. M.: Evaluation: from precision, recall and F-measure to ROC, informedness, markedness and correlation, J. Mach. Learn. Technol., 2, 37-63, 2011.

RCRCCC: Forecast-based Financing Practitioners Manual, available at: https://manual.forecast-based-financing.org/ (last access: 11 January 2021), 2020. reliefweb: Kenya: Floods and Landslides - Oct 2019, Tech. rep., reliefweb, available at: https://perma.cc/8C4Q-HTQQ (last access: 11 January 2021), 2019.

Robbins, J. and Titley, H.: Evaluating high-impact precipitation forecasts from the Met Office Global Hazard Map (GHM) using a global impact database, Meteorol. Appl., 25, 548-560, 2018.

Siderius, C., Gannon, K., Ndiyoi, M., Opere, A., Batisani, N., Olago, D., Pardoe, J., and Conway, D.: Hydrological response and complex impact pathways of the 2015/2016 El Niño in Eastern and Southern Africa, Earths Future, 6, 2-22, 2018.

Vitart, F., Ardilouze, C., Bonet, A., Brookshaw, A., Chen, M., Codorean, C., Déqué, M., Ferranti, L., Fucile, E., Fuentes, M., Hendon, H., Hodgson,J., Kang, H.-S., Kumar, A., Lin, H., Liu, G., Liu, X., Malguzzi, P., Mallas, I., Manoussak, M., Mastrangelo, D., MacLachlan, C., McLean, P., Minami, A., Mladek, R., Nakazawa, T., Najm, S., Nie, Y., Rixen, M., Robertson, A. W., Ruti, P., Sun, C., Takaya, Y., Tolstykh, M., Venuti, F., Waliser, D., Woolnough, S., Wu, T., Won, D.-J., Xiao, H., Zaripov, R., and Zhang, L.: The subseasonal to seasonal (S2S) prediction project database, B. Am. Meteorol. Soc., 98, 163-173, 2017.

Weingärtner, L., Jaime, C., Todd, M., Levine, S., McDowell, S., and MacLeod, D.: Reducing flood impacts through forecast-based action: Entry points for social protection systems in Kenya, Tech. rep., ODI - Overseas Development Insitute, available at: https://www.odi.org/sites/odi.org.uk/files/ resource-documents/12645.pdf (last access: 11 January 2021), 2018.

White, C. J., Carlsen, H., Robertson, A. W., Klein, R. J., Lazo, J. K., Kumar, A., Vitart, F., Coughlan de Perez, E., Ray, A. J., Murray, V., Bharwani, S., MacLeod, D., James, R., Fleming, L., Morse, A. P., Eggen, B., Graham, R., Kjellström, E., Becker, E., Pegion, K. V., Holbrook, N. J., McEvoy, D., Depledge, M., PerkinsKirkpatrick, S., Brown, T. J., Street, R., Jones, L., Remenyi, T. A., Hodgson-Johnston, I., Buontempo, C., Lamb, R., Meinke, H., Arheimer, B., and Zebiak, S. E.: Potential applications of subseasonal-to-seasonal (S2S) predictions, Meteorol. Appl., 24, 315-325, 2017.

Wilkinson, E., Weingärtner, L., Choularton, R., Bailey, M., Todd, M., Kniveton, D., and Cabot Venton, C.: Forecasting hazards, averting disasters: implementing forecast-based early action at scale, Tech. rep., ODI - Overseas Development Institute, London, available at: https://www.odi.org/sites/odi.org.uk/files/ resource-documents/12104.pdf (last access: 11 January 2021), 2018.

WMO: WMO Guidelines on Multi-Hazard Impact-Based Forecast and Warning Services, available at: https://library.wmo.int/ doc_num.php?explnum_id=7901 (last access: 11 January 2021), 2015 . 